\title{
Unique rheology of high acyl gellan gum and its potential applications in enhancement of petroleum production
}

\author{
Chang Hong Gao ${ }^{1}$
}

Received: 12 April 2015/Accepted: 29 October 2015/Published online: 13 November 2015

(c) The Author(s) 2015. This article is published with open access at Springerlink.com

\begin{abstract}
Gellan gum has been widely used as a food additive. This short communication investigates the rheological behavior of high acyl gellan gum. Experiments show that gellan gum achieves high viscosity in fresh water, but loses viscosity at high temperature. Besides, the viscosity of gellan gum is thermally reversible. The effects of monovalent ions and divalent ions on gellan gum are also tested. Sodium, potassium and calcium all have negative impacts on viscosity of gellan gum solutions. Compared with traditional polymer, gellan gum maintains high viscosity under high salinity. Thus, it can be applied in polymer flooding. On the other hand, the unique thermally reversible behavior makes gellan gum a candidate as fracturing fluid additive.
\end{abstract}

Keywords Gellan gum $\cdot$ Polymer rheology $\cdot$ Polymer application · Oil recovery $\cdot$ Fracturing fluid

\section{Introduction}

Gellan gum (GLG) is a polysaccharide produced by fermentation of a pure culture of Sphingomonas elodea. The polymer is a linear anionic heteropolysaccharide composed of tetrasaccharide repeating unit consisting of two $\beta$-D-glucose, one $\beta$-D-glucuronic acid and one $\alpha$-L-rhamnose residue (Grasdalen and Smidsrod 1987).

Gellan gum products are available in two types, high and low acyl content. Their structures are presented in

Chang Hong Gao

237184689@QQ.com

1 Sinopec Shengli E\&P Research Institute, Dongying, Shandong 257000, China
Fig. 1 (Kelco 2007). The low acyl gellan gum products form firm, non-elastic, brittle gels, whereas the high acyl gellan gum forms soft and elastic gels. Varying the ratios of the two forms of gellan produces a wide variety of textures (Gohel et al. 2009). The mechanism of gel formation is beyond the scope of this paper and can be found in the literature (Grasdalen and Smidsrod 1987).

Gellan gum has been approved by FDA to be used as a safe food additive. It has been widely adopted by the food industry. For example, GLG improves the texture of ice cream, milk, cookies, juices and jellies (Kelco 2007). Previously, many researchers studied the behavior of low acyl gellan gum (Miyoshi et al. 1994, 1996; Nitta and Nishinari 2005; Gohel et al. 2009). The research on high acyl GLG is very limited.

This paper is focused on the rheological behavior of high acyl GLG under the influences of temperature, monovalent and divalent ions. The author also discusses its potential applications in the petroleum industry.

\section{Materials and methods}

The high acyl gellan gum sample was provided by Tianwei chemical company in China. Other chemicals, including sodium chloride, potassium chloride, and calcium chloride were purchased from local suppliers. Rheology tests were conducted with OFITE rotational viscometer. GLG solutions were prepared with magnetic mixer and high-speed mixer.

The first step was to prepare GLG solutions. It was observed that high acyl GLG only partially dissolved in cool water at room temperature $\left(25^{\circ} \mathrm{C}\right)$. After heating, GLG dissolved in water and forms thick and milky fluid. When the solution cools down, it further thickens and

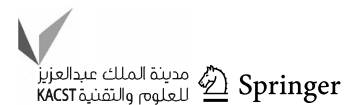




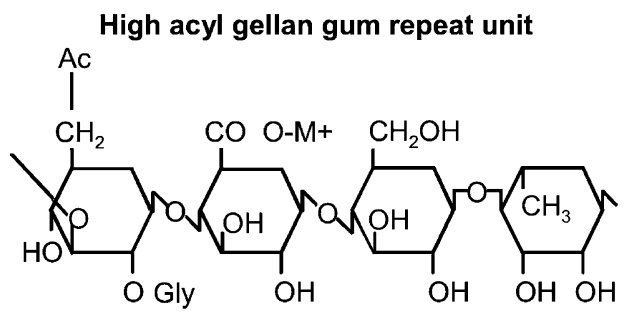

Low acyl gellan gum repeat unit

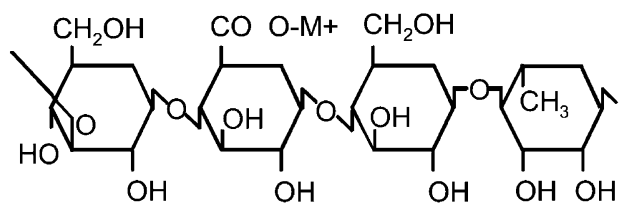

$A c=$ acetate group

Gly = glycerate group

Fig. 1 Molecular structure of Gellan Gum

forms a soft gel that easily breaks down under agitation and mixing.

Secondly, GLG was added to water at varied dosages to investigate the effect of GLG concentration on viscosity. Thirdly, GLG solutions were heated at high temperature to assess the effect of temperature on viscosity. Fourthly, $\mathrm{NaCl}, \mathrm{KCl}$, and $\mathrm{CaCl}_{2}$ were added to GLG solutions to quantify the effect of monovalent ions and divalent ions on viscosity. Finally, a core flooding experiment was conducted to evaluate the oil recovery with gellan gum. The test matrix is given in Table 1 .

For the recovery test, a Berea sandstone core was chosen and its properties were measured. The core sample had good porosity $(21 \%)$ and permeability $(90 \mathrm{mD})$. The rock pore volume was $15.5 \mathrm{~mL}$. The core flood tests followed standard recovery test procedures (Gao and Bellout 2013). The core was first saturated with brine, and then flooded with crude oil to irreducible water saturation (Swi). Afterwards, the same brine was injected to reach residual oil saturation (Sor). The oil recovery by water flooding is obtained. The second core flooding test followed the same procedures, but instead of brine, gellan gum solution containing $2 \mathrm{~g} / \mathrm{L}$ GLG was injected till residual oil saturation.

\section{Experimental results}

As mentioned in the previous section, gellan gum does not dissolve very well in cold water. While being heated, GLG completely dissolves in water and forms a viscous fluid. When cooling down, the solution further thickens and forms a weak gel. The fluid viscosity data before and after heating are presented in Fig. 2.

For both tests, the concentration of GLG was at $2 \mathrm{~g} / \mathrm{L}$, and both curves were measured at room temperature $\left(25^{\circ} \mathrm{C}\right)$. But the curve labeled before heating was obtained immediately after GLG was mixed with water at room temperature. The other curve, labeled after heating, was measured after the GLG solution was heated to $70{ }^{\circ} \mathrm{C}$, then cooled down to room temperature.

Figure 2 reveals the viscosity significantly increased after heating. This increase is much more pronounced at lower shear rate. For example, at a shear rate of 10/s, fluid viscosity before heating was around $103 \mathrm{cP}$, while the viscosity jumped to $1010 \mathrm{cP}$ after heating and cooling.

A polymer fluid must maintain high viscosity to effectively drive oil. Simply put, high polymer viscosity leads to high oil recovery. According to the data in Fig. 2, viscosity of gellan gum is boosted by preheating and cooling. This indicates that gellan gum should be preheated before injection into reservoir for EOR purpose. Preheating was applied in subsequent experiments.

Gellan gum was added to water at varied concentrations. The solutions were heated to $70{ }^{\circ} \mathrm{C}$, cooled to room temperature, and the viscosity was measured. As seen in Figs. 2 and 3, the relationships between viscosity and shear rate closely follow linear trends on $\log -\log$ plot. This indicates that GLG solutions demonstrate non-Newtonian behavior. Moreover, it is also obvious that higher GLG concentration leads to higher fluid viscosity. For example, the fluid viscosity was $190 \mathrm{cp}$ at low GLG concentration

Table 1 Summary of test matrix

\begin{tabular}{lllll}
\hline Test group & Objective of test & $\begin{array}{l}\text { Temperature } \\
(\text { deg.C) }\end{array}$ & $\begin{array}{l}\text { Gellan gum } \\
\text { concentration }(\mathrm{g} / \mathrm{L})\end{array}$ & Salt concentration (g/L) \\
\hline 1 & Study effect of GLG concentration & 25 & $1 ; 1.5 ; 2 ; 3$ & 0 \\
2 & Study effect of temperature & $25-60$ & 3 & 0 \\
3 & Study effect of $\mathrm{NaCl}$ & 25 & 2 & $10-50(\mathrm{NaCl}$ only) \\
4 & Study effect of $\mathrm{KCl}$ & 25 & 2 & $2-30(\mathrm{KCl}$ only) \\
5 & Study effect of $\mathrm{CaCl} 2$ & 25 & 2 & $20 \mathrm{~g} / \mathrm{L} \mathrm{NaCl,} \mathrm{plus} 30 \mathrm{~g} / \mathrm{L} \mathrm{CaCl2}$ \\
6 & Study oil recovery & 50 & 2 &
\end{tabular}


( $1 \mathrm{~g} / \mathrm{L})$ under low shear rate $(10 / \mathrm{s})$, but increased to $1820 \mathrm{cP}$ at high GLG concentration $(3 \mathrm{~g} / \mathrm{L})$.

To study the effect of temperature on viscosity, a solution containing $3 \mathrm{~g} / \mathrm{L}$ gellan gum was first heated to $70{ }^{\circ} \mathrm{C}$, then cooled to room temperature. The fluid was heated again to the desired temperature, and the viscosity data are given in Fig. 4. The rheological behavior is unique. When temperature increased, the viscosity of the GLG solution started to increase. However, the viscosity started to

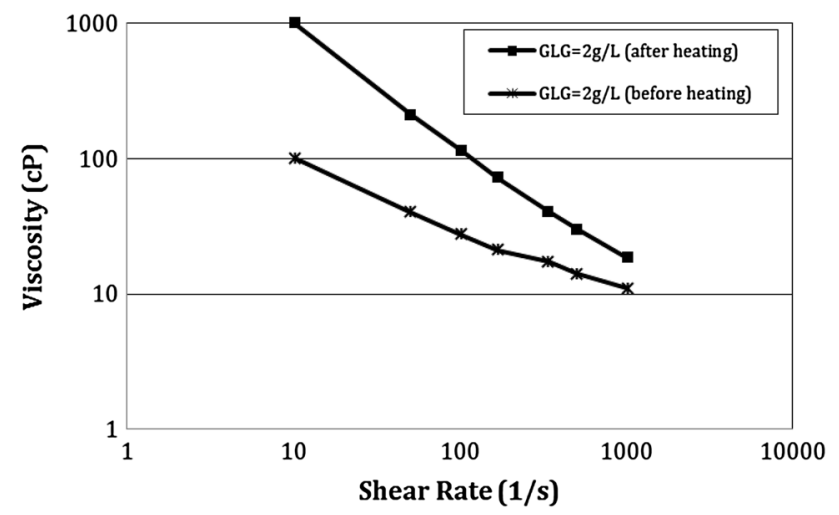

Fig. 2 Viscosity of GLG solutions before and after heating

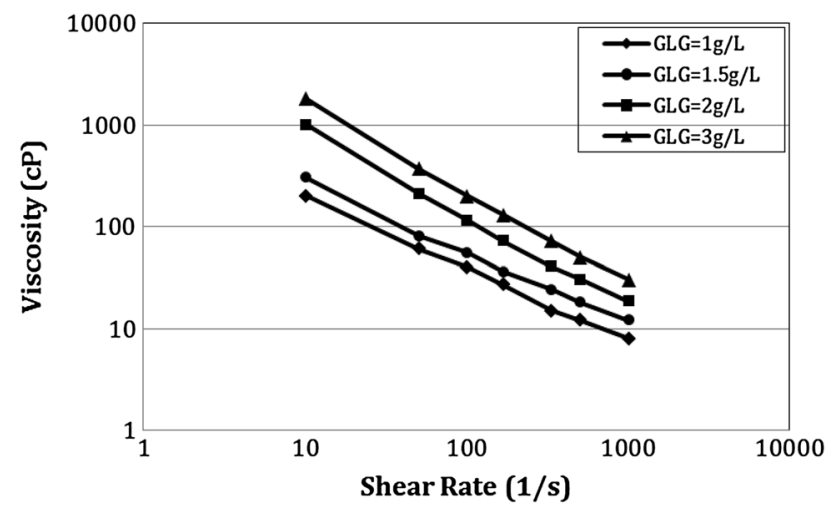

Fig. 3 Effect of GLG concentration on viscosity of GLG solution

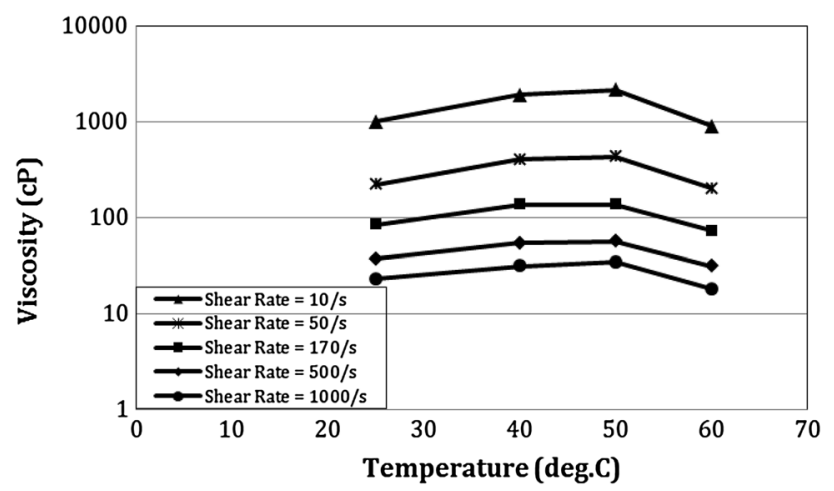

Fig. 4 Effect of temperature on viscosity of GLG solution decline after temperature reached $50{ }^{\circ} \mathrm{C}$. It was also observed that when the fluid cooled down, gellan gum almost fully recovered its viscosity. In other words, the viscosity of the gellan gum is thermally reversible.

Gellan gum solution containing $2 \mathrm{~g} / \mathrm{L}$ GLG was first heated to $70{ }^{\circ} \mathrm{C}$, and then cooled to room temperature. Afterwards, sodium chloride was added to the gellan gum solutions, and the viscosity was measured at room temperature. The test data are shown in Fig. 5. Sodium ion has significant influence on viscosity. When $\mathrm{NaCl}$ was added, solution viscosity quickly decreased. For instance, at a shear rate of $50 / \mathrm{s}$, when concentration of $\mathrm{NaCl}$ increased to $10 \mathrm{~g} / \mathrm{L}$, the viscosity dropped from 200 to $85 \mathrm{cP}$. After more $\mathrm{NaCl}$ was added, viscosity further reduced, but the reduction was not as significant.

Following the same test procedures, the effect of potassium ion was also assessed. The test data are given in Fig. 6. The trends are similar as those in Fig. 5. After $\mathrm{KCl}$ was added, the viscosity quickly declined. But the viscosity leveled off at higher concentration of potassium. Compared with $\mathrm{NaCl}$, the addition of $\mathrm{KCl}$ leads to more damage to fluid viscosity at low shear rate. At a shear rate of $10 / \mathrm{s}$, the viscosity reduced to $255 \mathrm{cP}$ when $10 \mathrm{~g} / \mathrm{L}$ sodium chloride was added. At the same shear and concentration, fluid viscosity was $204 \mathrm{cP}$ when $\mathrm{KCl}$ was introduced. While at high shear rate, both salts have very similar impacts on fluid viscosity.

It is believed polymer chains relax and extend in fresh water, resulting in high fluid viscosity. While concentration of monovalent ions increases, polymer chains begin to shrink and coil, leading to reduction in viscosity (Gao 2013).

To study the reaction of gellan gum to divalent ion, calcium chloride was added to GLG solutions. The same experimental procedures were carried out, and the test results are presented in Fig. 7. Calcium also has significant influence on fluid viscosity. Compared with $\mathrm{NaCl}$ and $\mathrm{KCl}$,

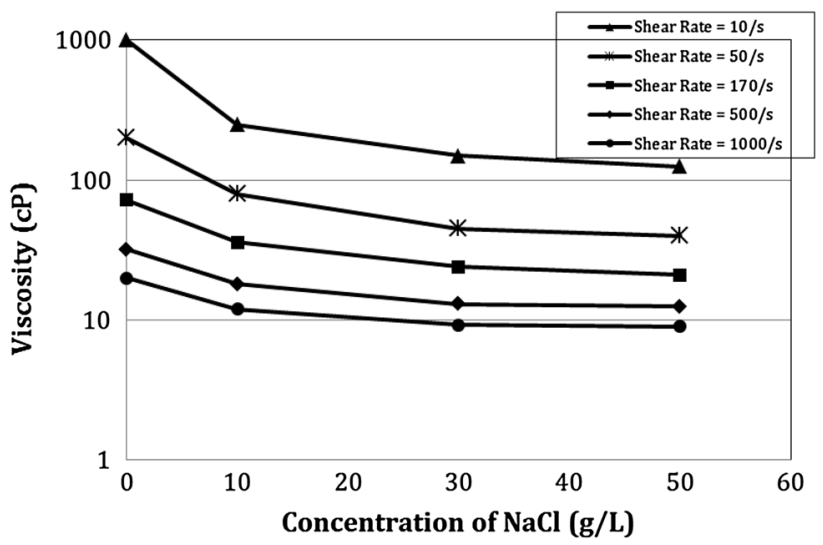

Fig. 5 Effect of $\mathrm{NaCl}$ concentration on viscosity of GLG solution

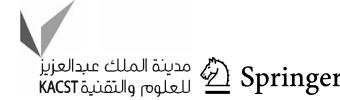




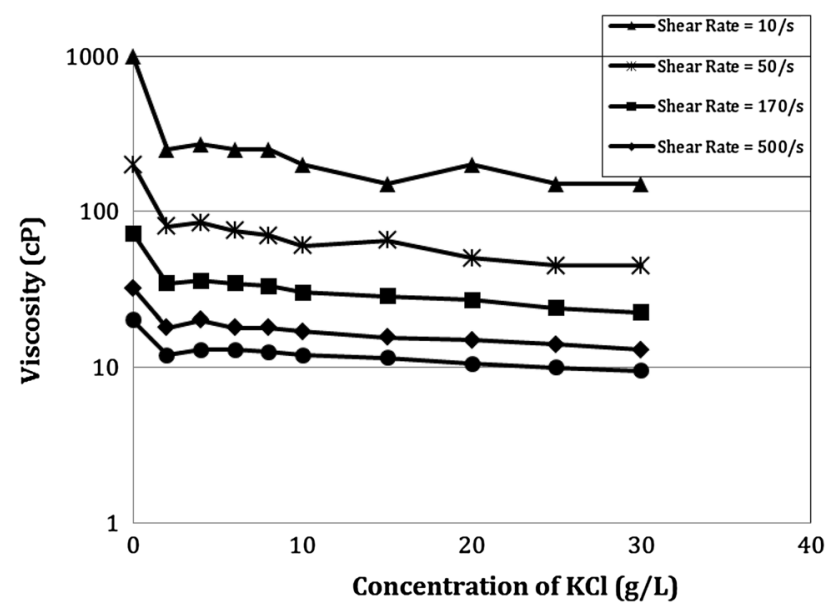

Fig. 6 Effect of $\mathrm{KCl}$ concentration on viscosity of GLG solution

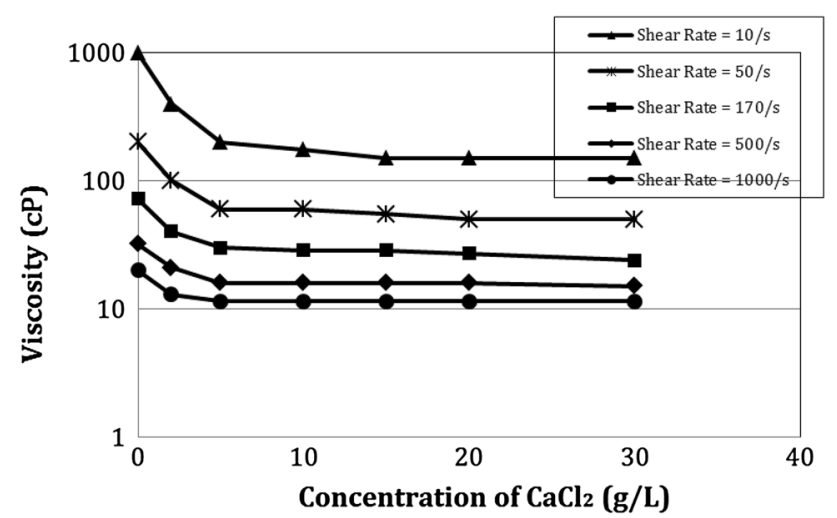

Fig. 7 Effect of $\mathrm{CaCl}_{2}$ concentration on viscosity of GLG solution

the addition of $\mathrm{CaCl}_{2}$ leads to more reduction to fluid viscosity at low shear rate. At a shear rate of 10/s, the viscosity reduced to $255 \mathrm{cP}$ when $10 \mathrm{~g} / \mathrm{L}$ sodium chloride was added. At the same shear and concentration, fluid viscosity was $177 \mathrm{cP}$ when calcium chloride was introduced. While at high shear rate, all salts have very similar impacts on fluid viscosity.

It is also meaningful to investigate the combined effects of monovalent ion and divalent ion on gellan gum. For this group of tests, the concentration of GLG was maintained at $3 \mathrm{~g} / \mathrm{L}$. As we can see from the data in Fig. 8, the fluid viscosity quickly declined after salts were introduced. But the viscosity of gellan gum stabilized at higher salt concentration.

The EOR test revealed that injection of gellan gum could not reduce residual oil saturation, but recovered $11 \%$ more oil after injection of 3 pore volumes of fluid. This indicates that injection of gellan gum can speed up the recovery process. However, the high acyl GLG can only be used in low temperature reservoirs, because it loses viscosity under high temperature (Fig. 4).

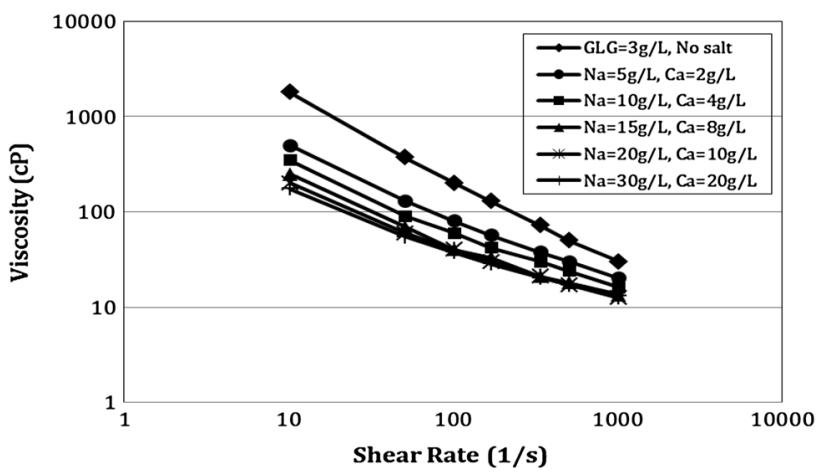

Fig. 8 Effect of salts combination on viscosity of GLG solution

Table 2 Yield point for gellan gum solutions

\begin{tabular}{llc}
\hline $\begin{array}{l}\text { Concentration of GLG } \\
(\mathrm{g} / \mathrm{L})\end{array}$ & Concentration of salt $(\mathrm{g} / \mathrm{L})$ & $\begin{array}{l}\text { YP }(\mathrm{lbf} / \\
\left.100 \mathrm{ft}^{\wedge} 2\right)\end{array}$ \\
\hline 1 & 0 & 8 \\
2 & 0 & 41 \\
3 & 0 & 44 \\
2 & $10 \mathrm{~g} / \mathrm{L} \mathrm{NaCl}$ & 24 \\
2 & $10 \mathrm{~g} / \mathrm{L} \mathrm{KCl}$ & 10 \\
2 & $10 \mathrm{~g} / \mathrm{L} \mathrm{CaCl} 2$ & 9 \\
3 & $30 \mathrm{~g} / \mathrm{L} \mathrm{NaCl}$, plus $20 \mathrm{~g} / \mathrm{L}$ & 9 \\
& $\mathrm{CaCl} 2$ & \\
\hline
\end{tabular}

\section{Discussion}

One potential application of gellan gum in petroleum industry is to enhance oil recovery. Polymer flooding has been successfully applied in Daqing field and Shengli field in China (Gao et al. 2014). HPAM (partially hydrolyzed polyacrylamide) has been the widely used polymer for commercial polymer injection projects. However, HPAM severely degrades under high salinity (Gao 2011, 2014). A previous study showed when sodium reached $10 \mathrm{~g} / \mathrm{L}$, viscosity of HPAM quickly dropped to below $50 \mathrm{cP}$ at a shear rate of 10/s (Gao 2013). While for gellan gum under the same salt concentration, its viscosity is still at $175 \mathrm{cP}$, as shown in Fig. 8.

On the other hand, gellan gum has the potential to serve as additive for fracturing fluid. During hydraulic fracturing operations, fracturing fluid (brine) carrying proppants is injected into wells. At low injection velocity (hence low shear rate), the fracturing fluid must maintain a high viscosity and yield point to effectively suspend and transport proppants. At high injection velocity (and high shear rate), the fracturing fluid should demonstrate low viscosity to reduce unnecessary pressure loss. After injection, the fracturing fluid should flow back easily and leave the proppants in the fracture.

Gellan gum matches these criteria. According to Fig. 3, gellan gum demonstrates high viscosity at low shear rate, but 
low viscosity at high shear rate. Besides, gellan gum shows high yield point (YP), especially at low salinity, as shown in Table 2. On the other hand, according to Fig. 4, viscosity of gellan gum solution declines at high temperature. This is also ideal for being used in fracturing fluid. After injection into pay zone, gellan gum fluid heats up and easily flows back.

\section{Conclusions}

(1) High acyl gellan gum achieves high viscosity in the fresh water at relatively low temperature. (2) Viscosity of gellan gum solution declines at high temperature, but its viscosity recovers when temperature reduces. (3) Sodium, potassium and calcium all have negative impacts on viscosity of gellan gum solutions. (4) Gellan gum has potential applications in EOR and hydraulic fracturing fluid.

Acknowledgments The author wants to thank Shandong Province government for funding this research work through Taishan scholar program.

Open Access This article is distributed under the terms of the Creative Commons Attribution 4.0 International License (http:// creativecommons.org/licenses/by/4.0/), which permits unrestricted use, distribution, and reproduction in any medium, provided you give appropriate credit to the original author(s) and the source, provide a link to the Creative Commons license, and indicate if changes were made.

\section{References}

Gao C (2011) Scientific research and field applications of polymer flood in heavy oil recovery. J Pet Explor Prod Technol 3(1):65-70

Gao C (2013) Viscosity of partially hydrolyzed polyacrylamide under shearing and heat. J Pet Explor Prod Technol 3(3):203-206

Gao C (2014) Empirical correlations for viscosity of partially hydrolyzed polyacrylamide. J Pet Explor Prod Technol 4(2):209-213. doi:10.1007/s13202-013-0064-z

Gao C, Bellout A (2013) An evaluation for two bacillus strains in improving oil recovery in carbonate reservoirs. Pet Sci Technol 31(11):1168-1174

Gao C, Shi J, Zhao F (2014) Successful polymer flooding and surfactant-polymer flooding projects at Shengli Oilfield from 1992 to 2012. J Pet Explor Prod Technol 4(1):1-8. doi:10.1007/ s13202-013-0069-7

Gohel M, Parikh R, Nagori S (2009) Preparation and evaluation of soft gellan gum gel. Indian J Pharm Sci 71(2):120-124. doi:10. 4103/0250-474X.54273

Grasdalen H, Smidsrod O (1987) Gelation of gellan gum. Carbohydr Polym 7(5):371-393. doi:10.1016/0144-8617(87)90004-X

Kelco (2007) Gellan gum book 5th edition, available at: http://www. cpkelco.com

Miyoshi E, Takaya T, Nishinari K (1994) Gel-sol transition in gellan gum solutions: rheological studies on the effects of salts. Food Hydrocoll 8(6):505-527

Miyoshi E, Takaya T, Nishinari K (1996) Rheological and thermal studies of gel-sol transition in gellan gum aqueous solutions. Carbohydr Polym 30(2):109-119

Nitta Y, Nishinari K (2005) Gelation and gel properties of polysaccharides gellan gum. J Biol Macromol 5(3):47-52 